\title{
Study of Influence of the Peak Current Time in Microstructure of a Coating Hard Made by GTAW-P Process
}

\author{
Eduardo Ferracin Moreira, Paulo Cezar Moselli, João Roberto Sartori Moreno \\ Federal Technological University of Paraná, Cornélio Procópio, Brazil \\ Email: duzinfmoreira@hotmail.com, moselli@utfpr.edu.br, joaosartori@utfpr.edu.br
}

Received 11 December 2015; accepted 25 December 2015; published 30 December 2015

Copyright (C) 2015 by authors and OALib.

This work is licensed under the Creative Commons Attribution International License (CC BY). http://creativecommons.org/licenses/by/4.0/

(c) (i) Open Access

\section{Abstract}

This paper presented analysis in order to show the influence of welding pulse parameters on the microstructure of the deposit, where a coating performed by GTAW-P process (Tungsten Arc Welding with the Atmosphere Gas with deposition Powder). The coating was an alloy of cobalt based on a substrate of a steel SAE 1020. The coating was performed with pulsed current between 120 and $180 \mathrm{~A}$, and the variations of pulse parameters occurred between the time base and peak currents. Metallographic analysis by electronic scanning microscopy (SEM), micro hardness testing and determination of the dilution rate of the material were carried out. Thus, the results demonstrated that sample 3 showed better results, such as the size of finer grains, medium high hardness about $65 \mathrm{HRC}, 4.3 \%$ dilution rate and a lower heat transfer. Therefore, the spectrum shown by scanning electron microscopy revealed the presence of hard carbides $(\mathrm{Co}, \mathrm{Cr}$ and $\mathrm{W})$ in interdendritic region of the deposit, which explained the high levels of hardness.

\section{Keywords}

Hard Coating, FCAW-P, Dilution, Pulse Parameters

Subject Areas: Mechanical Engineering

\section{Introduction}

Hard coating aims to realize the protection of the surface of equipment or mechanical part which is subject to severe operating conditions. The process consists in depositing on the desired surface, metal alloys with different mechanical properties of the substrate used. These alloys lead to more suitable strength to the equipment in 
order to make them more likely to wear at work.

The coating process is such that the cords are disposed laterally and a pair of nesting level so that the coating depends on the application and welding process [1].

The gas tungsten arc welding (GTAW) process is based on the electric arc established between a non-consumable tungsten electrode and of the work-pieces to be joined. GTAW also known as TIG welding (Tungsten Inert Gas), can be used small amounts of non-inert gases in the shielding mixture, such as hydrogen or nitrogen [2].

However, the Tungsten Process Atmosphere Gas (GTAW) or Tungsten Inert Gas (TIG) only performs deposition of the alloy by means of sticks or wires [3], suitable a welding nozzle adapted to perform the deposition of the alloy plating using in the form of powder material, which is called GTAW-P (Tungsten Arc Welding with the Gas atmosphere with Power deposition).

We note that these deposits should produce one dendritic solidification microstructure with complex carbides rich $\mathrm{Co}, \mathrm{Cr}$ and $\mathrm{W}$, originating from STELLITE 6 powder, formed in phase contours.

The great majority of Stellite alloys are cobalt-based, with additions of Cr, C, W and Mo consisting of complex carbides in an alloy matrix. They are resistant to wear, galling and corrosion and retain these properties at high temperatures. Their exceptional wear resistance is due mainly to the unique inherent characteristics of the hard carbide phase dispersed in a CoCr alloy matrix.

It is regarded as the industry standard for general-purpose wear resistance applications, has excellent resistance to many forms of mechanical and chemical degradation over a wide temperature range, and retains a reasonable level of hardness up to $500^{\circ} \mathrm{C}\left(930^{\circ} \mathrm{F}\right)$. It also has good resistance to impact and cavitation erosion [4].

They combine an excellent resistance to mechanical wear, especially at elevated temperatures with excellent corrosion resistance, and against sliding wear or wear due to friction metal. Alloys with high carbon content are usually more suitable to resist abrasion, worn by contact or severe erosion.

\section{Experimentation}

As substrate we used the SAE 1020 steel that has been rectified to remove oxides, oil and dirt and deposited by TIG welding the filler metal cobalt-based, commercially known as STELLITE 6 WM whose specification is illustrated in Table 1, but with a particle size between 45 and $180 \mu \mathrm{m}$ and $41.3 \mathrm{HRC}$ hardness, equivalent to 405 HV [5].

The experimental runs were performed on realization of a deposition with a device developed by a model multi-process welding machine Inversal 450 and an automatic feeder metal powder ADP-2 model, which we use as a shielding gas and drag the Argon. Table 2 shows the pulse parameters used, providing an average current pulse of approximately 150A, but with different peak time.

Each sample was cut and prepared abrasive paper \# 220 to \#1200, and then attacked in solution in $15 \mathrm{ml} \mathrm{H}_{2} \mathrm{O}$, $15 \mathrm{ml} \mathrm{HNO}_{3}, 15 \mathrm{ml} \mathrm{CH} \mathrm{COOH}_{3}$ and $60 \mathrm{ml} \mathrm{HCl}$ to reveal microstructure.

The grain sizes were valued according to ASTM E-112, but the hardness measurements were performed on the sample cross-section, a hardness equipment HV 1000B throughout the coating. The dilution was effected by macroscopic measurements of the value of the areas of penetration and strengthening the deposit as [6]. However, the heat input for this deposition abided between $200^{\circ} \mathrm{C}$ and $350^{\circ} \mathrm{C}$ as reported [7], which is responsible for

Table 1. Composition of coating powder.

\begin{tabular}{rccccccccc} 
& Co & Cr & W & C & Ni & Mo & Fe & Si & Others \\
\hline STELLITE 6 & Bal. & 30 & $4-5$ & 1.2 & $<3.0$ & $<1.0$ & $<3.0$ & $<2.0$ \\
\hline
\end{tabular}

Table 2. Pulse parameters.

\begin{tabular}{cccc}
\hline Parameters & Sample 1 & Sample 2 & Sample 3 \\
\hline Peak current (A) & 180 & 180 & 180 \\
Base current (A) & 120 & 120 & 120 \\
Peak time (ms) & 5 & 7,5 & 3 \\
\hline
\end{tabular}


modifying the substrate cooling time by changing the formation of the coating microstructure.

\section{Results and Discussions}

The deposit of coating is presented with a layer of $0.5 \mathrm{~mm}$ thick, less than $1 \%$ porosity and a hypo eutectic structure with various carbides dispersed as shown by macrographs of Figure 1 [7].

Figure 2, Figure 3 and Figure 4 show the micrographs obtained by optical microscopy (OM) and scanning electron microscopy (SEM) samples generated through the samples.

In welding coating, at the interface fact be the most critical region, the structure is more refined and heterogeneous, which may occur in this region increasing hardness [8].

To determine the principal components present in the coating a micro-analysis was performed in two stages bounded by regions (phases) A and B of the sample 1, as shown in Figure 5.

This structure have the typical hypo-eutectic performance consisting of complex wear resistant carbides dispersed in a tougher, more ductile CoCr alloy matrix. Higher levels of heat input resulted in the reduction of the ferrite content of the weld metal, but increasing the austenite.

The results with the phases present in the microstructure are shown in Table 3, which shows the phase rich in cobalt and iron, and B phase rich in chromium carbides, and tungsten in the form of dendritic needles.

The grain size data [9], hardness, dilution and heat input are shown in Table 4, where we can observe for sample 3, which besides having high hardness, showed lower heat input, lower average grain size and important dilution.
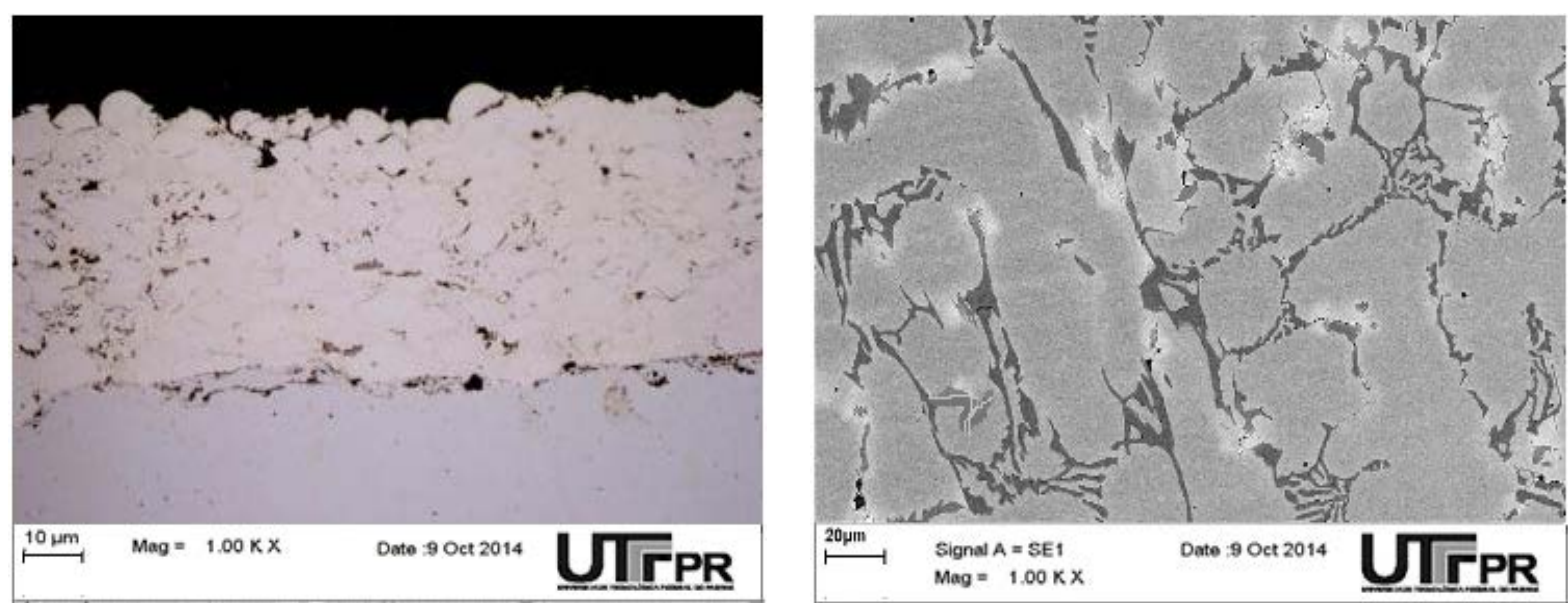

Figure 1. Macrograph and microtexture of the deposit in STELLITE 6 at 1000× magnification.
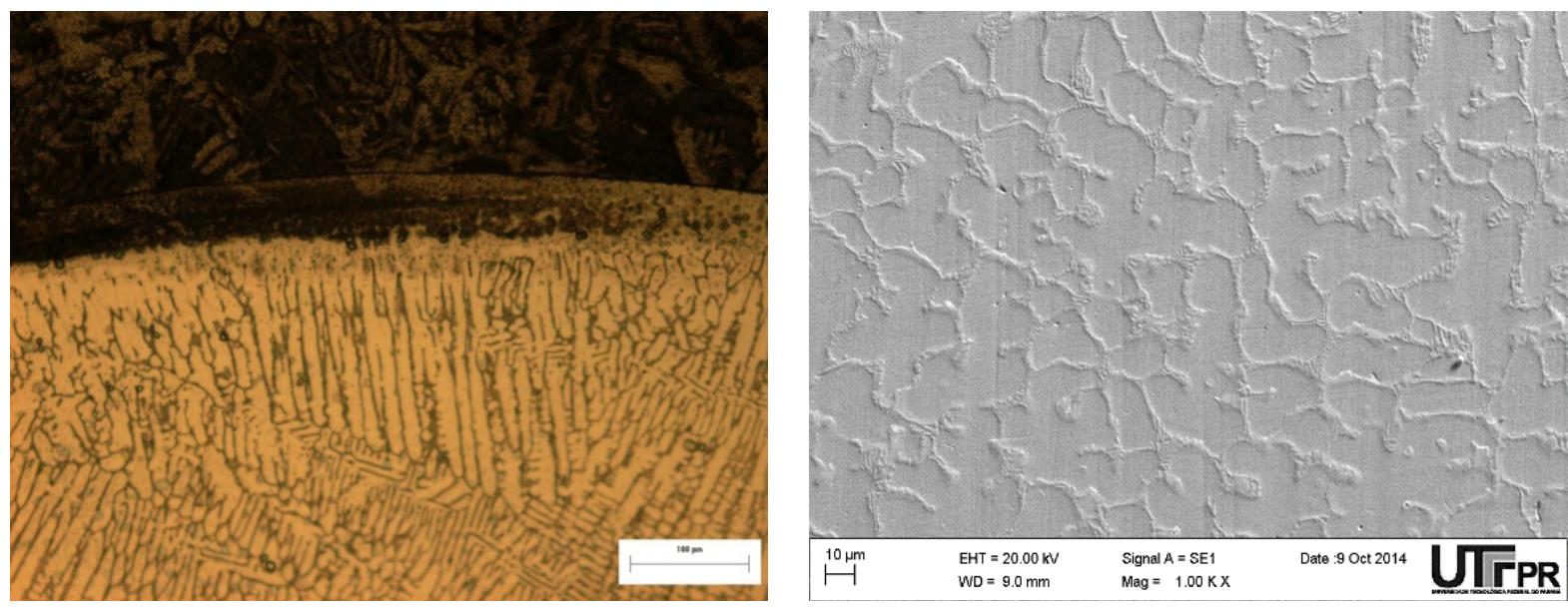

Figure 2. Lower region of the coating of sample 1 at $1000 \times$ magnification. 

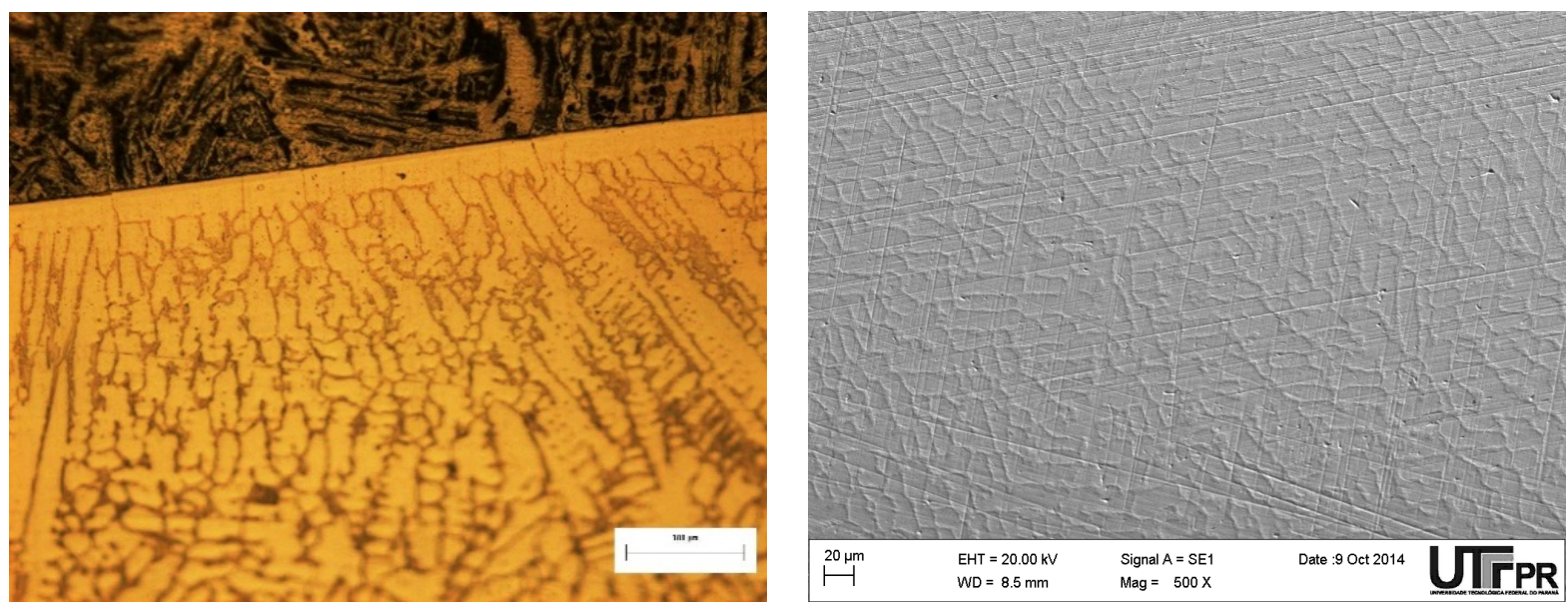

Figure 3. Lower region of the coating of sample 2 at $1000 \times$ magnification.
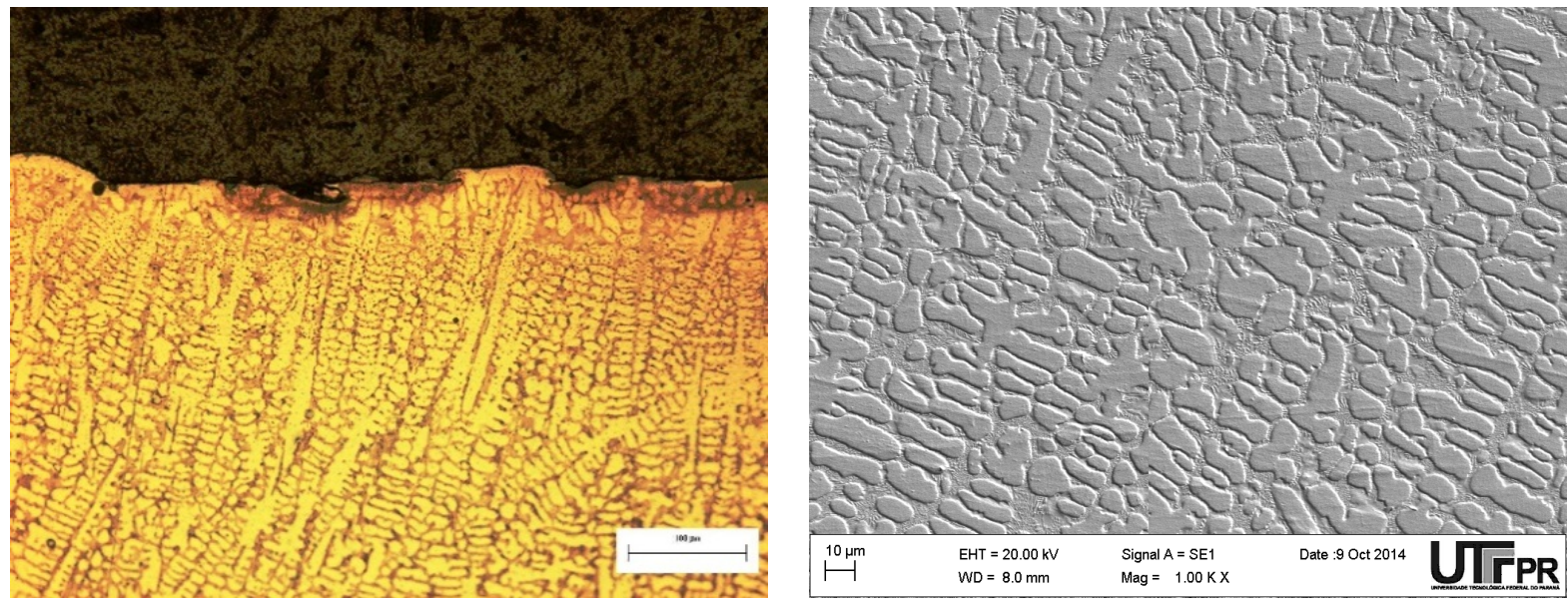

Figure 4. Lower region of the coating of sample 3 at $1000 \times$ magnification.

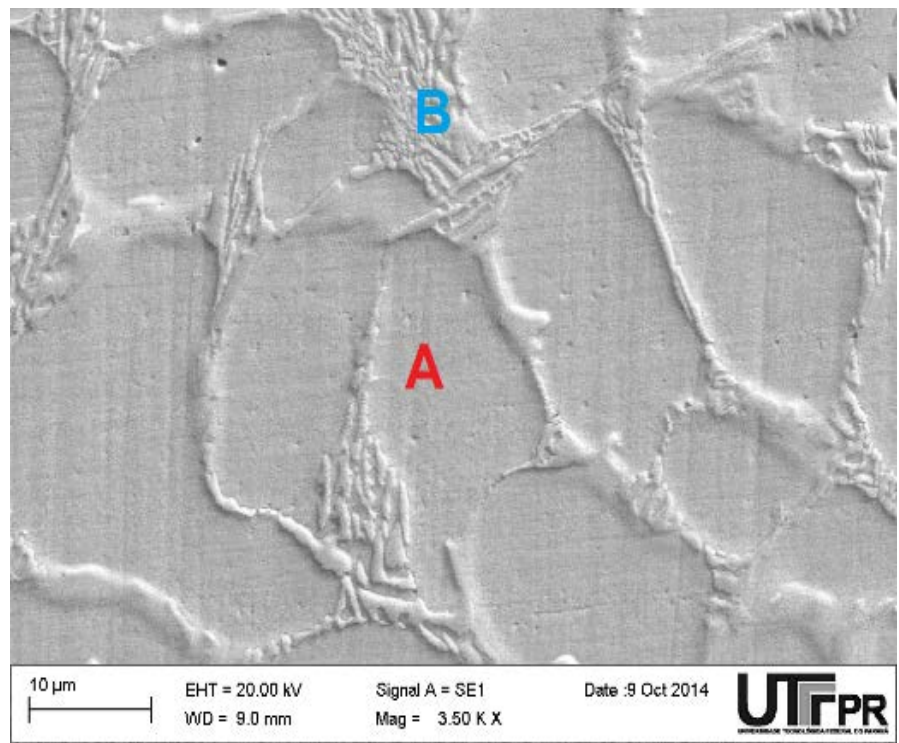

Figure 5. Phases of the applied coating, micro analyzed for sample 3 at $3500 \times$ magnification. 
Table 3. Chemical composition in weight (\%) of the phases A and B.

\begin{tabular}{ccc}
\hline Elements & Phase A (\%) & Phase B (\%) \\
\hline $\mathrm{Si}$ & 0.86 & 0.55 \\
$\mathrm{Cr}$ & 20.54 & 42.93 \\
$\mathrm{Fe}$ & 21.52 & 14.3 \\
$\mathrm{Co}$ & 51.31 & 34.46 \\
$\mathrm{Ni}$ & 1.7 & 1.04 \\
$\mathrm{~W}$ & 4.08 & 6.72 \\
\hline
\end{tabular}

Table 4. Properties obtained in coating.

\begin{tabular}{cccc}
\hline Results & Sample 1 & Sample 2 & Sample 3 \\
Grain Size $[\mu \mathrm{m}]$ & 143.9 & 166.7 & 133.3 \\
Hardness [HRC] & 60 & 65 & 65 \\
Dilution [\%] & 7.61 & 15.1 & 4.3 \\
Heat Input [KJ/mm] & 0.99 & 1.09 & 0.91 \\
\hline
\end{tabular}

\section{Conclusions}

It is noted across the micrograph and the standards for determining diameters of the grains, which, due to the low heat input, sample 3 was the one with a refined microstructure, greater hardness, since smaller grain sizes produce a microstructure homogeneously harder.

The lower heat input was also in the sample 3, which favored a better dilution. Microanalysis showed the significant difference of participation of the elements present in the coating, because in that phase $\mathrm{B}$ showed higher hardness than the layer A, the presence of elements such as $\mathrm{Cr}$ and Co was that generated the respective carbides for increasing the hardness. In addition to the hardness ratio, the higher share of carbon in the region $\mathrm{B}$ leads us to believe that there was the formation of chromium carbides and cobalt, which were characteristic of these deposits.

The welded sample 3 with a lower amount of heat input, showed the more refined structure and better mechanical properties to the weld.

\section{References}

[1] Gomes, J.H.F. (2010) Análise e otimização da soldagem de revestimento de chapas de aço ABNT 1020 utilização de arame tubular inoxidável austenítico. Master Thesis, Universidade Federal de Itajubá, Itajubá.

[2] Moselli, P.C., De Oliveira, M.F. and Moreno, J.R.S. (2013) Deposited Properties in Hardfacing SAE 1020 Substrate by Using Alloy Welding GTAW Stellite 6 in Powder Form. 22nd International Conference on Production Research, Fóz do Iguaçu.

[3] Ibrahim, I.A., Mohamat, S.A., Amir, A. and Ghalib, A. (2012) The Effect of Gas Metal Arc Welding (GMAW) Processes on Different Welding Parameters. Procedia Engineering, 41, 1502-1506. http://dx.doi.org/10.1016/j.proeng.2012.07.342

[4] Lakshminarayanan, A.K., Balasubramanian, V., Varahamoorthy, R. and Babu, S. (2008) Predicting the Dilution of Plasma Transferred Arc Hardfacing of Stellite on Carbon Steel Using Response Surface Methodology. Metals and Materials International, 14, 779-789. http://dx.doi.org/10.3365/met.mat.2008.12.779

[5] Buchely, M.F., Gutierrez, J.C., León, L.M.E. and Toro, A. (2005) The Effect of Microstructure on Abrasive Wear of Hardfacing Alloys. Tribology International, 259, 52-61. http://dx.doi.org/10.1016/j.wear.2005.03.002

[6] Karadeniz, E., Ozsarac, U. and Yildiz, C. (2007) The Effect of Process Parameters on Penetration in Gas Metal Arc Welding Processes. Material and Design, 28, 649-656. http://dx.doi.org/10.1016/j.matdes.2005.07.014

[7] Nunes, E.B., Cavalcante, N.E., Barreto, A.S., Silva, A.I.N. and Motta, M.F. (2015) Evaluation of the Effect of the Heat 
Input in the Super Stainless Steel Deposition by Powder Plasma Process. Soldagem \& Inspeção, 20.

[8] Liyanage, T., Fisher, G. and Gerlich, A.P. (2010) Influence of Alloy Chemistry on Microstructure and Properties in NiCrBSi Overlay Coatings Deposited by Plasma Transferred Arc Welding (PTAW). Surface and Coatings Technology, 205, 759-765. http://dx.doi.org/10.1016/j.surfcoat.2010.07.095

[9] Prasad, K.S., Rao, C.S. and Rao, D.N. (2011) A Study on Weld Quality Characteristics of Pulsed Current Micro Plasma Arc Welding of SS304L Sheets. International Transaction Journal of Engineering, Management, \& Applied Sciences \& Technologies, 2, 437-446. 